\title{
A Study of Metabolic Health in Very Old Individuals Residing in Central Arkansas
}

\author{
Azhar $\mathbf{G}^{1 * \#}$, Abraham RR ${ }^{1 \#}$, Girotra $\mathbf{M}^{2}$, Wei $\mathrm{JY}^{1}$, Foster $\mathrm{SR}^{1}$ and Schrader $\mathrm{AM}^{3}$ \\ ${ }^{1}$ Department of Geriatrics and Reynolds Institute of Aging, University of Arkansas for Medical Sciences, Little Rock, AR, USA \\ ${ }^{2}$ Division of Gastroenterology and Hepatology, Department of Medicine, University of Arkansas for Medical Sciences, Little Rock, AR, USA \\ ${ }^{3}$ Department of Biostatistics, College of Public Health, University of Arkansas for Medical Sciences, Little Rock, AR, USA \\ \#Both authors contributed equally
}

*Corresponding author: Azhar Gohar, Department of Geriatrics and Reynolds Institute of Aging, University of Arkansas for Medical Sciences, 4301 W. Markham, \#748 Little Rock, AR 72205-7199, USA, Tel: 501.526.5821; Fax: 501.526.7447; E-mail: azhargohar@uams.edu

Received date: March 05, 2015; Accepted date: July 01, 2015; Published date: July 08, 2015

Copyright: (c) 2015 Gohar A, et al. This is an open-access article distributed under the terms of the Creative Commons Attribution License, which permits unrestricted use, distribution, and reproduction in any medium, provided the original author and source are credited.

\begin{abstract}
Background: Metabolic syndrome is an important predictor of morbidity and mortality, the prevalence of which increases with age. Our report is part of the South-Central Study on Aging and defines the pattern of metabolic derangements observed in nonagenarians and centenarians living in Arkansas.

Methods: A retrospective study was undertaken of subject's $\geq 95$ years of age who had been patients at Reynold's Institute of Aging at University of Arkansas during the period of January 1, 2011 until June 13, 2013.

Results: Mean age of our patients was $97.5 \pm 2.9$ years (range=95-112 yrs). Among parameters of metabolic syndrome, our patients had mean systolic blood pressures of $141.1 \pm 24 \mathrm{mmHg}$ and diastolic pressure of $72.5 \pm 12$ $\mathrm{mmHg}(\mathrm{n}=109)$, with stage 1 or 2 hypertension present in 52/109 $(47.7 \%)$. Most patients had normal triglycerides (TG) levels, mean=120.6 $\pm 79.8 \mathrm{mg} / \mathrm{dL}$ (range=36-526 mg/dL) and only $12 / 53(22.6 \%)$ patients had high TG $>150$ $\mathrm{mg} / \mathrm{dL}$. Mean high-density (HDL) cholesterol ( $\mathrm{n}=52$ ) was $54.0 \pm 16 \mathrm{mg} / \mathrm{dL}$ (range=24-117 mg/dL). Mean low-density (LDL) levels $(n=53)$ were $122.4 \pm 39 \mathrm{mg} / \mathrm{dL}$. More than half $(29 / 53)$ had LDL levels $<130 \mathrm{mg} / \mathrm{dL}$ and $24 / 53(45.3 \%)$ had LDL of $\geq 130 \mathrm{mg} / \mathrm{dL}$. Mean glycosylated hemoglobin $(\mathrm{HbA} 1 \mathrm{C} ; \mathrm{n}=25)$ was $6.55 \pm 1.1 \%$ (range=5.30-10.6\%). Mean vitamin-D level ( $\mathrm{n}=41$ ) was $31.8 \pm 12 \mathrm{ng} / \mathrm{ml}$ (range=8-59 ng/ml), and low vitamin-D levels $(10-20 \mathrm{ng} / \mathrm{ml}) \mathrm{were}$ noted in $4 / 41(9.7 \%)$ with severe deficiency $(<10 \mathrm{ng} / \mathrm{ml})$ in $3 / 41(7.3 \%)$ patients. Similarly, abnormal thyroid stimulating hormone levels $(\mathrm{TSH} ; \mathrm{n}=57)$ were seen in only $4 / 57(7.0 \%)$ patients.
\end{abstract}

Conclusions: The majority of nonagenarian and centenarians in Arkansas were found to have a generally good metabolic profile, which could be a plausible explanation for the longevity of this aging cohort. However, various genetic, nutritional and epigenetic factors might have also contributed to the metabolic health of these individuals and will require further investigation.

Keywords: Metabolic health; Diabetes; Metabolic syndrome; Longevity; Dyslipidemia

\section{Introduction}

Metabolic health is an important predictor of morbidity and mortality. In 1988, Reaven et al. noted clustering of several cardiovascular risk factors (viz, dyslipidemia, hypertension, and hyperglycemia) and named it "Syndrome X" [1]. Progressively, other nomenclature like "insulin resistance syndrome" and "metabolic syndrome" gained favor to describe the grouping of these metabolic risk factors. The definition of metabolic syndrome per US National Cholesterol Education Program (NCEP) Adult Treatment Panel III includes 5 parameters, with at least 3 out of 5 required for the classification of metabolic syndrome [2]. The 5 parameters include: (i) abdominal obesity, defined as a waist circumference of $>40$ inches in men and 35 inches in females, atherogenic dyslipidemia, measured by (ii) elevated triglycerides (TG) of $\geq 150 \mathrm{mg} / \mathrm{dl}$ and (iii) low high density lipoprotein cholesterol $(\mathrm{HDL})<40 \mathrm{mg} / \mathrm{dL}$ in men and $<50$ $\mathrm{mg} / \mathrm{dL}$ in women, (iv) elevated blood pressure $\geq 130 / 85 \mathrm{mmHg}$, and (v) insulin resistance \pm glucose intolerance, measured by a fasting glucose of $\geq 100 \mathrm{mg} / \mathrm{dl}$. Individuals with metabolic syndrome are at increased risk for cardiovascular disease [3]. Besides cardiovascular diseases, patients with metabolic syndrome are more likely to have other health problems like diabetes, osteoporosis, frailty and a poor functional status. The Framingham cohort looked at the risk of newonset diabetes in both men and women, and determined metabolic syndrome to be a significant risk factor for predicting new-onset diabetes. The prevalence of metabolic syndrome also increases with age from $6.7 \%$ in the age group between $20-29$ years to $43.5 \%$ in the age group between 60-69 years [4,5]. However, in the very old metabolic syndrome has not been well studied, although cardiovascular diseases that cause early mortality appear to have a delayed onset in centenarians [4-7].

Interestingly, metabolic syndrome can be present in normal weight individuals because obesity is only one of the criteria constituting the metabolic disorder. A cross sectional survey by St-Onge et al. in 7,602 adults who participated in the Third National Health and Nutrition Examination Survey noted that although metabolic syndrome 
increased with body mass index (BMI), adults with a low BMI of 18.5-20.9 had a prevalence of metabolic syndrome between $0.9-3.0 \%$ [8]. Individuals in the upper normal weight range or those who were slightly overweight were found to have a relatively increased risk for metabolic syndrome. This concept of metabolically obese, normalweight individuals was developed over 20 years ago $[9,10]$.

Arkansas lies in the heart attack belt of the nation and the mortality from heart diseases is higher than the national average ( $228 \mathrm{vs.} 211$ per $100,000)$, making it the fifth highest in the country [11]. Arkansas is also above the national average in obesity, smoking, lower level of physical activity, diabetes, and high blood pressure. Our present report is part of the South-Central Study on Aging and defines the metabolic profile of the very old living in this region.

\section{Methods}

This study was conducted at Reynold's Institute of Aging at University of Arkansas for Medical Sciences (UAMS), Little Rock, Arkansas after obtaining approval from the Institutional Review Board (IRB). A retrospective chart review was conducted on all subjects $\geq 95$ years of age who were seen at UAMS during the period of January 1 , 2011 until June 13, 2013. Patients who were deceased, moved out of the state and had either no anthropometric/laboratory workup done at UAMS or had no such data from outside hospitals available for review, were excluded. After this selection, electronic medical records of 121 individuals were selected, and pertinent metabolic data were collected from the UAMS/Reynolds Institute of Aging data warehouse.

Data included age, gender, race, height, weight, body mass index (BMI), blood pressure (BP) including systolic (SBP) and diastolic (DBP), triglycerides (TG), low-density lipoprotein (LDL) cholesterol, high-density lipoprotein (HDL) cholesterol, glycosylated hemoglobin (HbAlc), random blood glucose, vitamin-D and thyroid stimulating hormone (TSH) levels. The protected health information (PHI) was handled according in a non-identifiable manner, and stored on password-protected departmental computers. The analyses were performed using SAS software (version 9.3, SAS Institute Inc., Cary, $\mathrm{NC}$ ). Continuous variables are presented as means \pm standard deviations which were calculated using the SAS procedure PROC MEANS, whereas categorical variables were calculated using the SAS procedure PROC FREQ. Due to the lack of normality in the distributions of age and BMI, the non-parametric Spearman rho was calculated to estimate correlation among age and BMI with other variables of interest using the SAS procedure PROC CORR including the Spearman option.

\section{Results}

General demographics: The demographic profile of the 121 Arkansans is presented in Table 1: 100 females (82.64\%), 21 males (17.36\%), with 86 (71.07\%) Caucasians, 34 (28.10\%) AfricanAmericans and 1 Hispanic $(0.83 \%)$ patients. The mean age was $97.5 \pm$ 2.98 years (range $=95-112$ years).

Our analysis revealed that only 7 (5.7\%) patients fulfilled the diagnosis of metabolic syndrome, with presence of at least 3 criteria as defined by NCEP-ATP III guidelines. Of these 7 patients with metabolic syndrome, 1 patient was obese, 2 were overweight and 3 had normal weight metabolic syndrome. One patient did not have height/ weight documented, but otherwise qualified as having metabolic syndrome based on other parameters. Of the remaining patients who did not fulfill the definition of metabolic syndrome, 23/121(19\%) had presence of 2 criteria and 64/121(52.8\%) had only one criterion present. Interestingly, 27/121 (22.3\%) patients did not meet any criteria for metabolic syndrome, but this could likely be due to missing information.

\begin{tabular}{|c|c|c|}
\hline & No. & $\%$ \\
\hline \multicolumn{3}{|l|}{ Age } \\
\hline \multirow{2}{*}{$\begin{array}{l}\text { Under } 99 \\
99 \text { or older }\end{array}$} & 89 & 73.55 \\
\hline & 32 & 26.45 \\
\hline \multicolumn{3}{|l|}{ Race } \\
\hline \multirow{3}{*}{$\begin{array}{l}\text { White } \\
\text { African American } \\
\text { Hispanic/Latino }\end{array}$} & 86 & 71.07 \\
\hline & 34 & 28.1 \\
\hline & 1 & 0.83 \\
\hline \multicolumn{3}{|l|}{ Gender } \\
\hline Male & 21 & 17.36 \\
\hline Female & 100 & 82.64 \\
\hline
\end{tabular}

Table 1: Demographics $(n=121)$.

Individual parameters of metabolic syndrome: Data on blood pressure were available in 109/121 patients. The mean systolic blood pressures were $141.08 \pm 24.22 \mathrm{mmHg}$ and diastolic pressure were $72.54 \pm 12.02 \mathrm{mmHg}$. When analyzed according to the Joint National Committee VII (JNC VII) definitions, stage 1 or 2 hypertension was present in 52/109 (47.7\%). There was a wide range in blood pressures, with the range of systolic and diastolic being $139 \mathrm{mmHg}$ and 80 $\mathrm{mmHg}$, respectively, and with 2 patients having systolic blood pressures over $200 \mathrm{mmHg}$. The pulse pressures tended to be high with more than $60 \%$ of the patients with pulse pressures over $50 \mathrm{mmHg}$.

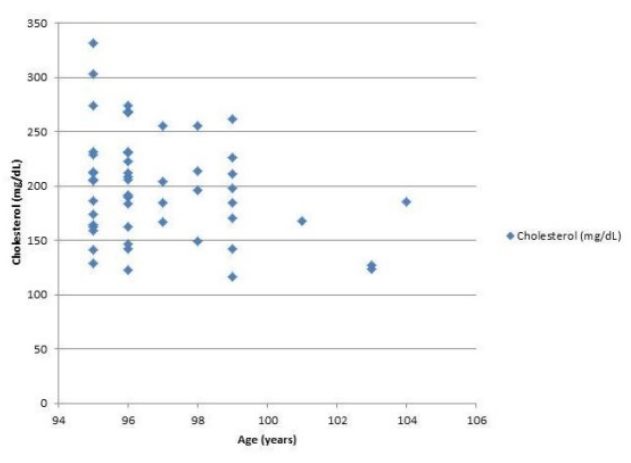

Figure 1a: Scatter plot of age with total cholesterol.

Data on lipids, including total cholesterol, TG, LDL and HDL were available in a subset of patients. Approximately $20 \%$ of patients had total cholesterol over $240 \mathrm{mg} / \mathrm{dL}$ and $45 \%$ of the patients had an LDL over $130 \mathrm{mg} / \mathrm{dL}$ (Figs. 1a and 1b). It was observed that most patients $(n=53)$ had normal TG levels, with mean being $120.57 \pm 79.78 \mathrm{mg} / \mathrm{dL}$ (range $=36-526 \mathrm{mg} / \mathrm{dL}$ ) and only $12 / 53(22.6 \%)$ patients had high TG>150 mg/dL. Total cholesterol and LDL showed a tendency 
Page 3 of 5

towards a slight decrease with increasing age (Figure 1a and 1b). A borderline significant inverse correlation was detected between age and triglycerides where triglyceride levels decrease as age increases: rho $=-0.26$ with a $\mathrm{p}$-value of 0.0567 (Figure 1c).

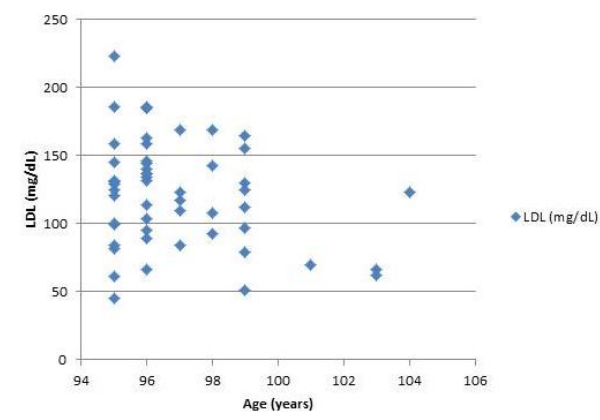

Figure 1b: Scatter plot of age with low density lipoprotein (LDL).

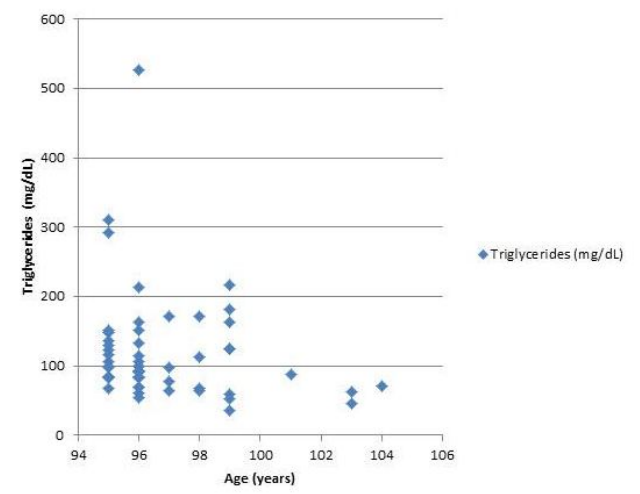

Figure 1c: Scatter plot of age with triglycerides (TRI).

HDL cholesterol $(n=52)$ was within the recommended range in $45 / 52$ patients (86.5\%), with a mean of $54.04 \pm 16.26 \mathrm{mg} / \mathrm{dL}$ (range $=24-117 \mathrm{mg} / \mathrm{dL}$ ). Approximately $17 \%$ of patients had HDL less than $40 \mathrm{mg} / \mathrm{dL}$ and $31 \%$ had HDL more than $60 \mathrm{mg} / \mathrm{dL}$.

Glycosylated hemoglobin ( $\mathrm{HbAlC}$ ), which is a measure of 3-month glycemic index, was available in 25 patients, and the mean value was $6.55 \pm 1.12 \%$ (range $=5.3-10.6 \%$ ). Notably, A1C levels of $\geq 5.7 \%$ were counted as deranged glucose, as proposed by American Diabetes Association (ADA), however, it should emphasized that the HbA1C range for geriatric patients is higher than that employed for younger adults. Forty percent of the patients in our study had HbAlC values over $6.5 \%$ and 3 patients had values over $8.0 \%$. In general, $\mathrm{HbA1C}$ appeared to increase with decreasing BMI, but the correlation between $\mathrm{HbA1C}$ and BMI was not statistically significant ( $\mathrm{rho}=0.19, \mathrm{p}=0.4022$ ).

As the fifth parameter of metabolic syndrome, waist circumference is suggested by NCEP, which unfortunately was not documented for any of our patients. However, World Health Organization (WHO) and International Diabetes Federation (IDF) guidelines suggest that if body mass index (BMI) is $>30 \mathrm{~kg} / \mathrm{m}^{2}$, central obesity can be assumed and waist circumference does not need to be measured. In our cohort, 37 patients $(37 / 121=30.5 \%)$ had no documented weights or heights to calculate BMI. Of the remaining 84 patients who had documented heights and weights, 47/84 (56.0\%) patients had normal BMI (18.5-25), 29/84 (34.5\%) patients were overweight (BMI 25-30) and $6 / 84(7.1 \%)$ patients were obese (with BMI greater than 30). Only 2 patients had a BMI below the normal range (18.15 and 16.5). In this small cohort, BMI and total cholesterol were not significantly correlated ( $\mathrm{rho}=0.06, \mathrm{p}=0.6810$ ), and BMI and diastolic blood pressures were also not significantly correlated ( $\mathrm{rho}=0.11, \mathrm{p}=0.3389$ ). However, at the alpha level of 0.1 , a significant positive correlation existed between BMI and systolic blood pressures (rho=0.19, $\mathrm{p}=0.0819$-Figure 2).

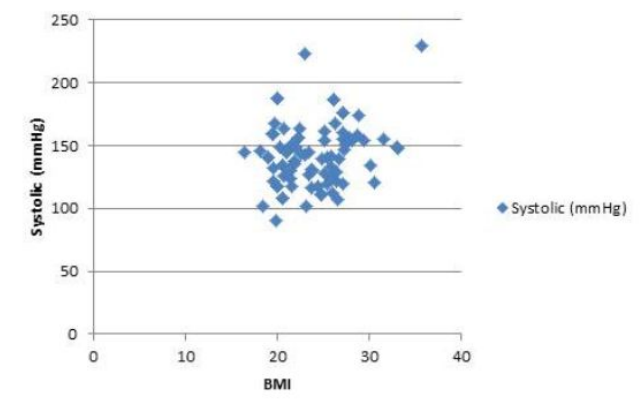

Figure 2: Scatter plot of body mass index (BMI) with systolic blood pressure (SBP).

Additional health parameters recorded: Mean vitamin-D level $(\mathrm{n}=41)$ was $31.78 \pm 12.45 \mathrm{ng} / \mathrm{mL}$ (range $=8-59 \mathrm{ng} / \mathrm{mL}$ ). Low vitamin $\mathrm{D}$ levels (between 10-20 ng/ml) were noted in $4 / 41(9.76 \%)$ and severe deficiency $($ level $<10 \mathrm{ng} / \mathrm{ml})$ in only $3 / 41(7.3 \%)$ patients. The data suggest a significant inverse correlation between Vitamin $D$ and age with Vitamin D levels decreasing as age increases: $r h o=-0.3, p=0.0264$ (Figure 3).

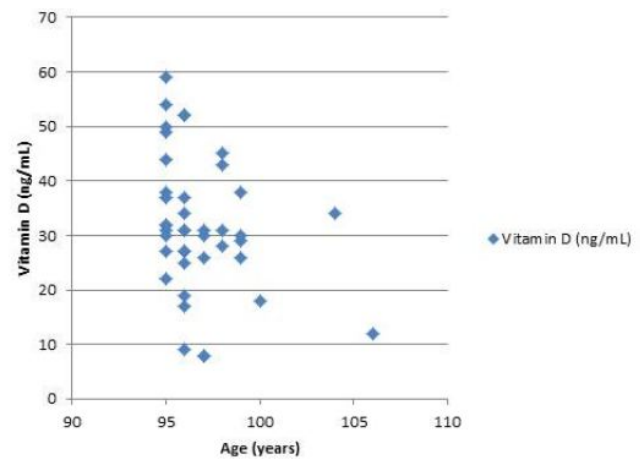

Figure 3: Scatter plot of age with Vitamin D. 
Mean TSH ( $\mathrm{n}=57)$ was $2.16 \pm 1.55 \mathrm{mIU} / \mathrm{L}$, and $93 \%$ of the patients had normal thyroid function with abnormal levels noted in only $4 / 57$ patients.

\section{Discussion}

Contrary to our initial expectation, the majority of nonagenarian and centenarians in Central Arkansas (part of South Central US) were found to have normal blood pressure, lipid profile and $\mathrm{HbA1C}$, which does not mirror the overall metabolic profile of the general population of this region. Thyroid function and Vitamin D levels were also within the normal range in a high percentage of patients.

It has been postulated that among centenarians who have survived longer, a significant component of this may be familial $[12,13]$. Altmann-Schneider et al. evaluated the brain tissue integrity among 185 offspring of centenarians and found that they have a decreased risk for developing age related conditions such as loss of white matter from the corpus callosum (genu and body), independent of metabolic risk factors [13]. It may well be that the prevalence and implications of metabolic risk factors would be different in this population compared with younger seniors.

A number of studies have looked at the metabolic risk factors in offspring of centenarians. A study done by Ostan et al. looked at 265 offspring of centenarians and compared them to 101 offspring of nonlong-lived parents, and found that although prevalence rates of metabolic syndrome were similar in the offspring of centenarians and the controls, centenarians' offspring with metabolic syndrome seemed healthier, more functionally fit, and had lower resistin levels [14]. One theory proposed by this study pointed to changes in the cytokine network that leads to a chronic inflammatory status with aging with dysregulation of metabolism [14]. They also found that the offspring of centenarians were on fewer medications including cardiovascular, lipid-lowering, and antihypertensive therapiesand had a lower prevalence of abdominal obesity as compared to controls. In our study, we also found that the majority of our subjects had a normal BMI, and there is no significant correlation between age and BMI (rho $=-0.09$, $\mathrm{p}=0.4143$ ). It has also been shown in other studies that over the age of 65 , the association between BMI and the risk of coronary heart disease are much weaker $[15,16]$. Interestingly, the American Heart Association (AHA) recommends intentional weight loss for subjects with heart failure only if the BMI is over 40 [17]. In addition, AHA recommends weight loss for adults with BMI over 35 only if they have 2 additional cardiovascular risk factors, such as hypertension or diabetes [17]. Our data suggest that a higher BMI did not appear to be incompatible with longevity, although more studies will need to be done to determine if it confers any protection in very old age, similar to that observed in congestive heart failure patients with obesity [18]. A number of reasons have been cited for the obesity paradox, including the potentially greater muscle mass and strength, a better metabolic reserve capacity and protection against cachexia. It is possible that the BMI ranges used for adults cannot be applied to nonagenarians and centenarians. Another study performed by Rozing et al. reported that the offspring of long-lived parents have a lower prevalence of metabolic syndrome than their partners despite having a comparable body composition $[19,20]$. Moreover, a study by Galioto et al. postulated that centenarians and their offspring may avoid bad habits such as smoking and/or alcohol use and that this lifestyle difference may partially contribute to their good health [19-21].
We also reviewed a number of other criteria of the metabolic syndrome such as hypertension, dyslipidemia and diabetes mellitus. Both systolic and diastolic blood pressures were variable in our patients, with a few outliers having systolic blood pressures over 200 mmHg. The current guidelines from the Eight Joint National Committee (JNC8) recommend treatment of blood pressures in individuals over the age of 60 to keep pressures under $150 / 90 \mathrm{mmHg}$ [22]. A study of centenarians in Poland concluded that slightly higher blood pressures in the very old might be beneficial for their health [23]. We do not have data on the management of hypertension for these individuals over a few years preceding these measurements so it is difficult to determine if the very high systolic blood pressures were sporadic acute events. Nevertheless, it is interesting to note that the patients even survived with systolic blood pressures over $180 \mathrm{mmHg}$ in this age group. The majority of individuals had a pulse pressure over $50 \mathrm{mmHg}$, and some considerably higher. Both high and low pulse pressures are associated with increased morbidity and mortality in adults with normal blood pressure or hypertension; however, our data suggest that in the very old, the same risks might not be applicable and the decision to treat will need to be individualized [24,25]. Diabetes mellitus tends to show an age-related increase even in centenarians. In the prospective Georgia centenarian study, the prevalence of diabetes mellitus defined as $\mathrm{HbA1C}$ value more than 6.5 $\%$ was $12.5 \%$ [26]. In our data $\mathrm{HbAlC}$ was available for a small number of subjects, but $40 \%$ had values more than $6.5 \%$. The difference in prevalence could also be secondary to diet or treatment effects that we have not analyzed in this study.

Vitamin D levels generally exhibit an age-associated reduction due to a number of factors including poor nutrition and a lower intake of calcium and vitamin D containing food. In addition, reduced exposure to sunlight and renal impairment reduces the conversion of 25hydroxyvitamin D (25-OH vitamin D) to the active form $(1,25$ dihydroxyvitamin $\mathrm{D}$ ). The intestinal receptors also diminish with age, further reducing the absorption of vitamin D in the elderly [27]. In our study, in the subset in whom vitamin $\mathrm{D}$ had been measured, more than half had levels over $31 \mathrm{ng} / \mathrm{ml}$; however, within these elderly subjects, Vitamin D and BMI are not significantly correlated (rho $=-0.11$, $\mathrm{p}=0.5004)$. Nevertheless, considering that Vitamin $\mathrm{D}$ is stored in fat, it is more likely for it to be normal in subjects with higher BMI values. Thyroid function has also been investigated in several studies in the very old [28-30]. The study by Atzmon et al suggested that TSH levels increase with extreme longevity with an inverse correlation with free thyroxin (FT4) levels, which might have a beneficial role in longevity [29]. Another study on centenarians conducted in Denmark demonstrated no significant difference in thyroid dysfunction in centenarians versus young or older adults [30]. Our data were more in accord with the Danish study with normal TSH levels in over $90 \%$ of patients in whom it was recorded.

To our knowledge, this is the first report from South Central United States, highlighting the overall metabolic profile of nonagenarians and centenarians. While studies showing trends of overall health and general medical conditions in Arkansas residents reflect a high prevalence of cardiovascular disease, diabetes, and obesity, our study suggests a different prevalence of these conditions in people who have lived longer. This leads us to propose that a healthy metabolic profile could be a plausible explanation for the longevity of this population subset. Our study had a few limitations, chiefly missing data, which could have led to underestimation of the overall prevalence of metabolic syndrome. The missing data together with a few outliers combined to reduce the statistical inference that could be drawn from 
the results. However, this is not unusual in retrospective studies of the elderly and in spite of these potential shortcomings, our study is novel in bringing forth the metabolic profile of people living in the MidSouth, specifically of Central Arkansas, who likely have done "something right", perhaps including having the ideal genetic profile or "right parents", to have made it well into the nonagenarian and centenarian age group (over age 94 years).

\section{Conclusion}

In this study from Arkansas, we have highlighted that nonagenarians and centenarians, despite variable blood pressures, have overall normal lipid profiles, HbA1C, Vitamin D and TSH levels. Their metabolic health does not mirror the overall metabolic profile of the general population in this region. We propose that this healthy metabolic profile could be a plausible explanation for their overall health, although other contributing factors, such as dietary, socioeconomic, life-style and genetic influence may also have played a role in their longevity. An investigation of these factors will be of interest in future studies of exceptional aging.

\section{Conflicts of Interest and Disclosures}

The Claude D. Pepper Older American Independence Center Grant (AG28718) provided partial support for this research.

\section{References}

1. Reaven GM (1988) Banting lecture 1988. Role of insulin resistance in human disease. Diabetes 37: 1595-1607.

2. Third report of the National Cholesterol Education Program (NCEP) expert panel on detection, evaluation, and treatment of high blood cholesterol in adults (Adult Treatment Panel III). (2002) Final report. Circulation 106: 3143-3342.

3. Lakka HM, Laaksonen DE, Lakka TA, Niskanen LK, Kumpusalo E, et al. (2002) The metabolic syndrome and total and cardiovascular disease mortality in middle-aged men. JAMA 288: 2709-2716.

4. Cameron AJ, Shaw JE, Zimmet PZ (2004) The metabolic syndrome: prevalence in worldwide populations. Endocrinol Metab Clin North Am 33: 351-375, table of contents.

5. Ford ES, Giles WH, Dietz WH (2002) Prevalence of the metabolic syndrome among US adults: findings from the third National Health and Nutrition Examination Survey. JAMA 287: 356-359.

6. Sumner AD, Sardi GL, Reed JF 3rd (2012) Components of the metabolic syndrome differ between young and old adults in the US population. J Clin Hypertens (Greenwich) 14: 502-506.

7. Luo L, Yang M, Hao Q, Yue J, Dong B (2013) Cross-sectional study examining the association between metabolic syndrome and cognitive function among the oldest old. J Am Med Dir Assoc 14: 105-108.

8. St-Onge MP, Janssen I, Heymsfield SB (2004) Metabolic syndrome in normal-weight Americans: new definition of the metabolically obese, normal-weight individual. Diabetes Care 27: 2222-2228.

9. Ruderman NB, Schneider SH, Berchtold P (1981) The "metabolicallyobese," normal-weight individual. Am J Clin Nutr 34: 1617-1621.

10. Ruderman NB, Berchtold P, Schneider S (1982) Obesity-associated disorders in normal-weight individuals: some speculations. Int J Obes 6 Suppl 1: 151-157.

11. Mujib M, Zhang Y, Feller MA, Ahmed A (2011) Evidence of a "heart failure belt" in the southeastern United States. Am J Cardiol 107: 935-937.
12. Gavrilov LA, Gavrilova NS (2015) New Developments in the Biodemography of Aging and Longevity. Gerontology 61: 364-371.

13. Altmann-Schneider I, de Craen AJ, Veer IM, van den Berg-Huysmans AA, Slagboom PE, et al. (2013) Preserved white matter integrity is a marker of familial longevity. Ann Neurol 74: 883-892.

14. Ostan R, Bucci L, Cevenini E, Palmas MG, Pini E, et al. (2013) Metabolic syndrome in the offspring of centenarians: focus on prevalence, components, and adipokines. Age (Dordr) 35: 1995-2007.

15. Ninomiya $T$ (2011) Is metabolic syndrome a risk factor for cardiovascular disease in late elderly? Am J Hypertens 24: 1193.

16. Rimm EB, Stampfer MJ, Giovannucci E, Ascherio A, Spiegelman D, et al. (1995) Body size and fat distribution as predictors of coronary heart disease among middle-aged and older US men. Am J Epidemiol 141: 1117-1127.

17. Jense M, Ryan D, Apovian C, Ard JD, Comuzzie A et al. (2013) AHA/ACC/TOS Guidelines for the management of overweight and obesity in adults. J Am Coll Cardiol. 2014; 63(25_PA): 2985-3023.

18. Lavie CJ, De Schutter A, Milani RV (2015) Healthy obese versus unhealthy lean: the obesity paradox. Nat Rev Endocrinol 11: 55-62.

19. Ostan R, Bucci L, Cevenini E, Palmas MG, Pini E, et al. (2013) Metabolic syndrome in the offspring of centenarians: focus on prevalence, components, and adipokines. Age (Dordr) 35: 1995-2007.

20. Rozing MP, Westendorp RG, de Craen AJ, Frölich M, de Goeij MC, Heijmans BT, BeekmanM,Wijsman CA,Mooijaart SP, Blauw GJ, Slagboom PE, van Heemst D, Leiden Longevity Study Group (2010) Favorable glucose tolerance and lower prevalence of metabolic syndrome in offspring without diabetes mellitus of nonagenarian siblings: the Leiden Longevity. Study. J Am Geriatr Soc 58: 564-569.

21. Galioto A, Dominguez LJ, Pineo A, Ferlisi A, Putignano E, Belvedere M, Costanza G, Barbagallo M (2008) Cardiovascular risk factors in centenarians. Exp Gerontol 43: 106-113.

22. James PA, Oparil S, Carter BL, Cushman WC, Dennison-Himmelfarb C, et al. (2014) 2014 evidence-based guideline for the management of high blood pressure in adults: report from the panel members appointed to the Eighth Joint National Committee (JNC 8). JAMA 311: 507-520.

23. Szewieczek J, Dulawa J, Francuz T, Legierska K, Hornik B, et al. (2015) Mildly elevated blood pressure is a marker for better health status in Polish centenarians. Age (Dordr) 37: 9738.

24. Benetos A, Rudnichi A, Safar M, Guize L (1998) Pulse pressure and cardiovascular mortality in normotensive and hypertensive subjects. Hypertension 32: 560-564.

25. Yildiran T, Koc M, Bozkurt A, Sahin DY, Unal I, et al. (2010) Low pulse pressure as a predictor of death in patients with mild to advanced heart failure. Tex Heart Inst J 37: 284-290.

26. Davey A, Lele U, Elias MF, Dore GA, Siegler IC, et al. (2012) Diabetes mellitus in centenarians. J Am Geriatr Soc 60: 468-473.

27. Johnson MA, Davey A, Park S, Hausman DB, Poon LW; Georgia Centenarian Study (2008) Age, race and season predict vitamin D status in African American and white octogenarians and centenarians. J Nutr Health Aging 12: 690-695.

28. Mariotti S, Barbesino G, Caturegli P, Bartalena L, Sansoni P, et al. (1993) Complex alteration of thyroid function in healthy centenarians. J Clin Endocrinol Metab 77: 1130-1134.

29. Atzmon G, Barzilai N, Hollowell JG, Surks MI, Gabriely I (2009) Extreme longevity is associated with increased serum thyrotropin. J Clin Endocrinol Metab 94: 1251-1254.

30. Andersen-Ranberg K, Jeune B, Høier-Madsen M, Hegedüs L (1999) Thyroid function, morphology and prevalence of thyroid disease in a population-based study of Danish centenarians. J Am Geriatr Soc 47: 1238-1243. 